\title{
Circulating Microparticles from Patients with Septic Shock Exert Protective Role in Vascular Function
}

\author{
Hadj Ahmed Mostefai ${ }^{1}$, Ferhat Meziani ${ }^{1,2}$, Maria Letizia Mastronardi ${ }^{1}$, Abdelali Agouni ${ }^{1}$, Christophe Heymes ${ }^{3}$, \\ Cyrille Sargentini², Pierre Asfar², Maria Carmen Martinez ${ }^{1}$, and Ramaroson Andriantsitohaina ${ }^{1}$ \\ ${ }^{1}$ INSERM U771, CNRS UMR 6214, and Université d'Angers, and ${ }^{2}$ Service de Réanimation Médicale, Centre Hospitalier Universitaire d'Angers, \\ Angers; and ${ }^{3}$ INSERM U689, Paris, France
}

\begin{abstract}
Rationale: Sepsis is an archetypal condition with molecular links between inflammation and coagulation. Both events can be orchestrated by the interaction between circulating and vascular cells that under activation release microparticles.

Objectives: We characterized circulating microparticles from both nonseptic subjects and patients with septic shock and evaluated their contribution to vascular function.

Methods: Circulating microparticles and their cell origin were measured in blood from 36 patients with septic shock and 18 nonseptic subjects by flow cytometry. Microparticles were then injected intravenously into mice and vascular reactivity was assessed in aorta. Expression and activity of enzymes involved in nitric oxide (NO) and cyclooxygenase metabolite production were analyzed.

Measurements and Main Results: Circulating levels of microparticles and platelet- and endothelial-derived microparticles were increased in septic patients. Surprisingly, septic microparticles enhanced the sensitivity of contraction of mouse aorta in response to serotonin. Interestingly, septic microparticles enhanced the contraction of aorta from lipopolysaccharide-treated mice. This effect was linked neither to increased calcium entry nor to Rho kinase inhibitor-sensitive mechanisms. In addition, the effect of septic microparticles was not modified either by NO-synthase or cyclooxygenase- 2 inhibitors, and was not associated with $\mathrm{NO}$ or $\mathrm{O}_{2}{ }^{-}$overproduction. The nonselective cyclooxygenase- 2 inhibitor indomethacin reduced, and the specific thromboxane $A_{2}$ antagonist SQ-29548 abolished, aortic contraction in mice treated with nonseptic and septic microparticles. The effect of septic microparticles was associated with increased thromboxane $A_{2}$ production, and was sensitive to a selective thromboxane $A_{2}$ antagonist. Conclusions: We provide evidence that increased circulating microparticles are protective against vascular hyporeactivity accounting for hypotension in patients with septic shock.
\end{abstract}

Keywords: microvesicles; vasomotricity; cyclooxygenase; oxidative stress; sepsis

Sepsis is the most important cause of death among hospitalized patients, with mortality rates ranging from 30 to $70 \%$. Sepsis is the result of an acute and systemic immune response to a variety of noxious insults, in particular to bacterial infection (1-3). This response leads to the activation of a number of host mediator systems, including the cytokine, leukocyte, and hemostatic

(Received in original form December 17, 2007; accepted in final form August 19, 2008) Supported by institutional grants from the Fondation pour la Recherche Médicale (nos. INE20050303433 and INE20060306500), Fonds Européen pour le Développement Régional (no. 8891), CNRS, INSERM, and Université d'Angers. R.A. was supported by a Contrat d'Interface INSERM. H.A.M. and A.A. are recipients of a doctoral fellowship from Conseil Régional du Pays de la Loire and French Education Ministry, respectively.

Correspondence and requests for reprints should be addressed to R. Andriantsitohaina, Ph.D., INSERM U771, Faculté de Médecine, Rue Haute de Reculée, Angers, F-49045 France. E-mail: ramaroson.andriantsitohaina@univ-angers.fr

This article has an online supplement, which is accessible from this issue's table of contents at www.atsjournals.org

Am J Respir Crit Care Med Vol 178. pp 1148-1155, 2008

Originally Published in Press as DOI: 10.1164/rccm.200712-18350C on August 21, 2008

Internet address: www.atsjournals.org

\section{AT A GLANCE COMMENTARY}

Scientific Knowledge on the Subject

Although several studies have shown that circulating microparticles are elevated during severe sepsis, the origin and the role played by these microparticles in the regulation of vascular function are not known.

What This Study Adds to the Field

Increased circulating microparticles are protective against vascular hyporeactivity, and are associated with hypotension in patients with septic shock.

networks, each of which may contribute to the pathological sequelae of sepsis. A severe form of sepsis is associated with evidence of organ dysfunction (i.e., tissue hypoperfusion and hypoxia, lactic acidosis, oliguria, or altered cerebral function). Thus, sepsis has been classically considered as the archetypal clinical condition in which evident molecular links between inflammation and coagulation can be observed.

Both inflammation and thrombosis can be orchestrated by the interactions between circulating cells, such as lymphocytes, platelets, vascular cells, endothelial cells, and smooth muscle cells, which under activation or apoptosis lead to the release of circulating microparticles (MPs) (4). MPs are membrane vesicles with procoagulant and proinflammatory properties (4, 5). MPs are present in blood from healthy individuals and elevated in patients in pathological states, such as sepsis, preeclampsia, Crohn's disease, and diabetes, strengthening the notion that MPs may play a role in these diseases (4). Indeed, MPs can be considered as vectors of biological messages, such as induction of endothelial and vascular dysfunctions or platelet activation (5). Regarding sepsis, patients with meningococcal sepsis display elevated numbers of MPs originating from platelets and granulocytes that are procoagulant in terms of their capacity to stimulate the generation of thrombin (6). Furthermore, volunteers receiving an infusion of endotoxin exhibit an early increase in circulating MPs associated with tissue factor and procoagulant activity, and especially those from $\mathrm{CD} 14^{+}$monocyte-derived MPs and to a less extent endothelial-derived MPs (7). Moreover, in patients with severe sepsis, lower levels of endothelial, platelet, and leukocyte MPs have been associated with a higher mortality rate and organ dysfunction (8). In the latter study, excessive nitric oxide (NO) production in leukocytes seemed to be associated with lower survival rate. This is not surprising inasmuch as NO is one of the key players in cardiac, vascular, renal, and pulmonary derangements of sepsis (9). The increased endogenous NO production is caused by enhanced expression of the inducible form of NO synthase (iNOS), at least in part in the vessel wall as demonstrated in vessels from septic 
human patients (10). All the preceding studies provide information about the probable role of circulating MPs during sepsis.

To the best of our knowledge, the origin and the role played by circulating MPs in the regulation of vascular function during severe sepsis are not known, although a prolonged or excessive drop in peripheral resistance may cause progressive hypotension, refractory to catecholamines, and contribute to life-threatening cardiovascular failure in this disease.

Therefore, the aim of this study was first to isolate and characterize circulating MPs from septic patients and second to assess their effect on vascular reactivity and on $\mathrm{NO}$ and $\mathrm{O}_{2}{ }^{-}$ production. The mechanisms by which septic MPs affect vascular contractility were also investigated. MPs were injected intravenously into mice to test their pathophysiological relevance in vivo.

\section{METHODS}

\section{Patients}

This study was approved by the Ethics Committee of the Sociéte de Réanimation de Langue Française (Angers, France). The study included patients with $(\mathrm{n}=36)$ and without $(\mathrm{n}=18)$ septic shock. Septic shock was defined according to standard criteria of the American College of Chest Physicians/Society of Critical Care Medicine Consensus Conference, 1992 (11).

Baseline characteristic of patients with septic shock (male, $81 \%$; female, $19 \%$ ) are shown in Table 1. Patients with preexistent chronic inflammatory disease, diabetes mellitus, obesity, and cancer or leuko-neutropenia were not included. Also, the sources of sepsis are shown in Table 1. Pathogens were identified in 15 patients: 8 patients with gram-positive bacteria and 7 with gram-negative bacteria. Patients without evidence of infection and with normal hemodynamics were considered control subjects (male, 56\%; female, $44 \%$ ). All nonseptic patients were referred to our intensive care unit for monitoring and control of their blood pressure.

\section{Blood Cell Preparation}

Peripheral blood $(20 \mathrm{ml})$ from nonseptic and septic patients was collected from a peripheral vein into sodium citrate tubes (Vacutainers; Becton Dickinson, Le Pont de Claix, France) during the early phase of septic shock ( $10 \pm 4 \mathrm{~h}$ after enrollment in the intensive care unit). Samples were centrifuged as previously described (12). Levels of endotoxin were assessed in all MP preparations with a Limulus amebocyte lysate kit (QCL-1000; Lonza, Walkersville, MD) and were found to be below the lower detection limit of the kit $(<0.1$ endotoxin unit $/ \mathrm{ml})$.

\section{Characterization of MP Phenotype}

Membrane MP subpopulations were discriminated in platelet-free plasma according to the expression of membrane-specific antigens by flow cytometry. Sample analysis was stopped after the count of 10,000 events.

\section{Vascular Reactivity}

All animal studies were performed according to approved institutional protocols. Male Swiss mice (8-10 wk old) were treated in vivo by intravenous injection via the tail vein of MPs at the circulating levels of MPs detected in the blood of each patient (septic MPs) or nonseptic subjects (nonseptic MPs), as previously performed in other pathologies $(13,14)$. In another set of experiments, mice were treated with vehicle or LPS (40 mg/kg, intraperitoneal); 2 hours later, MPs from septic patients were injected as described previously. After 24 hours, aortic rings were isolated and mounted on a wire myograph filled with physiological salt solution for measurement of vascular reactivity as previously described $(15,16)$.

\section{Determination of Prostanoid Production}

Thromboxane $\mathrm{A}_{2}$, prostaglandin E metabolites, prostacyclin, and total 8 -isoprostanes were measured with enzyme immunoassays kits (Cayman Chemicals, Ann Arbor, MI).

\section{NO Determination by Electron Paramagnetic Resonance}

Aorta was incubated for NO production as previously described $(15,17)$.
TABLE 1. BASELINE CHARACTERISTICS OF NONSEPTIC AND SEPTIC PATIENTS

\begin{tabular}{lcc}
\hline & $\begin{array}{c}\text { Nonseptic Patients } \\
(n=18)\end{array}$ & $\begin{array}{c}\text { Septic Patients } \\
(n=36)\end{array}$ \\
\hline Age, yr & $49 \pm 20$ & $65 \pm 14$ \\
Sex ratio, M/F & $10 / 8$ & $29 / 7$ \\
Mean infusion rate of norepinephrine & 0 & $1.1 \pm 0.4 \mu \mathrm{g} / \mathrm{kg} / \mathrm{min}$ \\
Mortality at $28 \mathrm{~d}, \%$ & 0 & 28 \\
SAPS II & $6 \pm 2$ & $55 \pm 23$ \\
SOFA score & 0 & $10 \pm 3^{*}$ \\
Body mass index, kg/m² & $23 \pm 4$ & $25 \pm 5$ \\
Source of infection, \% & & \\
$\quad$ Pulmonary & & 47 \\
$\quad$ Abdominal & & 17 \\
$\quad$ Cutaneous & & 17 \\
$\quad$ Urinary & & 11 \\
$\quad$ Other & & 8
\end{tabular}

Definition of abbreviations: SAPS = simplified acute physiology score; SOFA = sequential organ failure assessment.

* $P<0.01$ versus nonseptic patients.

\section{Superoxide Anion Spin Trapping}

Aorta was treated for 60 minutes with deferoxamine-chelated KrebsHEPES solution containing 1-hydroxy-3-methoxycarbonyl-2,2,5,5tetramethylpyrrolidine $(\mathrm{CMH}, 500 \mu \mathrm{mol} / \mathrm{L}$; Noxygen, Elzach, Germany), deferoxamine $(25 \mu \mathrm{mol} / \mathrm{L})$, and diethyldithiocarbamate (DETC, $5 \mu \mathrm{mol} / \mathrm{L}$ ). The reaction was stopped by putting the samples in ice. They were frozen in liquid $\mathrm{N}_{2}$ and analyzed by electron paramagnetic resonance.

\section{Western Blotting}

Blots were performed as previously described (15).

\section{Data Analysis}

Data are expressed as means \pm SEM, and $n$ represents the number of experiments. Statistical analyses were performed by two-way analysis of variance, and nonparametric Mann-Whitney U tests or analysis of variance for repeated measures and subsequent Bonferroni post hoc test. $P<0.05$ was considered to be statistically significant.

See the online supplement for additional details on the methods for making these measurements.

\section{RESULTS}

\section{Circulating Level of MPs Is Increased in Septic Patients Compared with Healthy Subjects}

The total number of circulating MPs was significantly increased in septic patients compared with nonseptic subjects (Figure 1A). Phenotypic characterization of the cellular origin of MPs showed an increase of 1.7- and 3-fold of the circulating level of plateletand endothelial-derived MPs, respectively, in septic patients compared with nonseptic subjects (Figures $1 \mathrm{~A}$ and 1B). Also, $\mathrm{L}^{-}$-selectin ${ }^{+}$and $\mathrm{P}$-selectin ${ }^{+}$MPs were increased in septic patients compared with nonseptic subjects (5- and 2.5-fold, respectively; Figure 1B), whereas MPs from leukocytes $\left(\mathrm{CD} 45^{+}\right)$were reduced by about $13 \%$ (Figure 1B). MPs of other cellular origins were not significantly different between the two groups, including those from granulocytes $\left(\mathrm{CD}_{6} 6 \mathrm{~b}^{+}\right)$, monocytes and macrophages $\left(\mathrm{CD} 11 \mathrm{~b}^{+}\right)$, and erythrocytes (CD235a ${ }^{+}$) (data not shown). Furthermore, septic patients did not display increased procoagulant MPs that were annexin $\mathrm{V}^{+}$compared with nonseptic subjects.

\section{Septic MPs Do Not Affect Endothelial Responses Compared with Nonseptic MPs in Mouse Aorta}

The relaxation in response to acetylcholine was not significantly different between aortas taken from mice subjected to intravenous injection of either nonseptic MPs or septic MPs $\left(E_{\max }\right.$, 

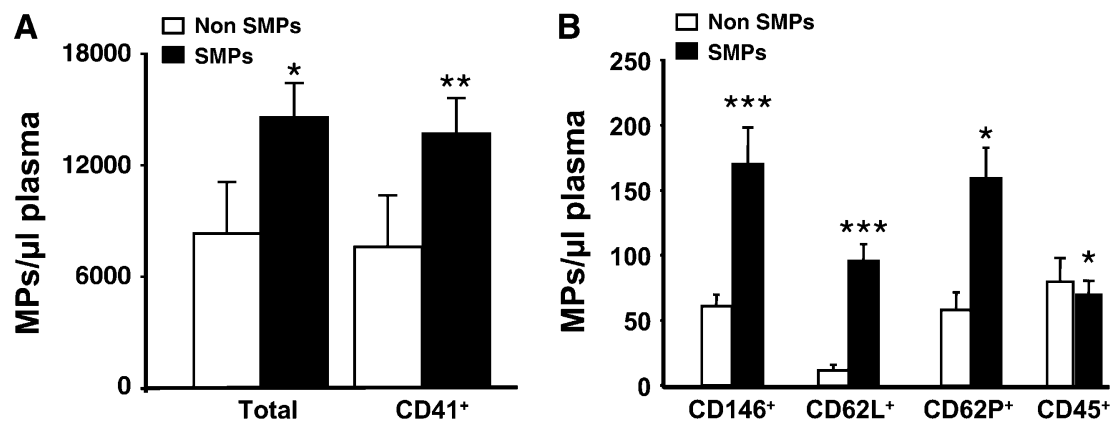

Figure 1. Circulating microparticle (MP) levels in patients with septic shock compared with healthy subjects. Shown are circulating MP levels in various populations: $(A)$ platelet-derived $\left(\mathrm{CD} 41^{+}\right) \mathrm{MPs} ;(B)$ endothelium-derived $\left(\mathrm{CD} 146^{+}\right) \mathrm{MPs}$, L-selectin ${ }^{+}$ $\left(\mathrm{CD} \mathrm{L}^{+}\right) \mathrm{MPs}$, P-selectin ${ }^{+}\left(\mathrm{CD} \mathrm{P}^{+}\right) \mathrm{MPs}$, and leukocyte-derived $\left(\mathrm{CD}^{4} 5^{+}\right) \mathrm{MPs}$ from nonseptic subjects (nonseptic microparticles [Non SMPs]) and patients with septic shock (septic microparticles [SMPs]). ${ }^{*} P<$ $0.05 ;{ }^{* *} P<0.01 ;{ }^{* * *} P<0.001$

$55 \pm 6$ and $46 \pm 8 \%$, respectively) (Figure $2 \mathrm{~A}$ ). These results suggest that septic MPs did not affect endothelium-dependent vasodilation compared with nonseptic MPs.

\section{Septic MPs Increase Responsiveness of Mouse Aortic Rings to Vasoconstrictor Agents}

Serotonin (5-HT) produced a concentration-dependent increase in tension in mouse aortic rings with functional endothelium in the control group (CTL), as well as in those treated with circulating levels of either nonseptic or septic MPs (Figure 2B). The responses to 5-HT were less stable in aortas taken from septic MP-treated mice than in aortas taken from CTL or nonseptic MP-treated mice, and increasing the 5-HT concentration from 1 to $10 \mu \mathrm{mol} / \mathrm{L}$ caused a rapid and pronounced decline in tension in aortas from septic MP-treated mice. However, the maximal contraction induced by 5 -HT was not significantly different in aortas from all groups. Interestingly, the sensitivity of contraction in response to 5-HT was increased in aortas taken from mice treated with septic MPs $\left(\mathrm{pD}_{2}, 7.13 \pm 0.06\right)$ compared with those taken from CTL mice $\left(\mathrm{pD}_{2}, 6.23 \pm 0.02\right)$ or those treated with nonseptic MPs $\left(\mathrm{pD}_{2}, 6.32 \pm 0.04\right)(P<0.01)$ (Figure $\left.2 \mathrm{~B}\right)$.

\section{Septic MPs Do Not Affect Voltage-dependent $\mathrm{Ca}^{2+}$ Channels} or Rho Kinase Pathway

The mechanisms by which septic MPs enhanced sensitivity to 5-HT were further investigated on the pathways linked to either
$\mathrm{Ca}^{2+}$ entry or $\mathrm{Ca}^{2+}$ sensitization via Rho kinase. In aortic rings from septic- and nonseptic MP-treated mice exposed to $\mathrm{KCl}$ $(80 \mathrm{mmol} / \mathrm{L})$ in $\mathrm{Ca}^{2+}$-free medium, cumulative addition of $\mathrm{CaCl}_{2}$ produced concentration-dependent contraction. Under these conditions, septic MPs did not affect the contractile response to $\mathrm{CaCl}_{2}$ compared with nonseptic MPs $\left(\mathrm{pD}_{2}, 2.48 \pm 0.12\right.$ vs. $2.59 \pm 0.12$, respectively) (Figure 2C). To test whether the ability of septic MPs to increase the vascular sensitivity of aorta to 5-HT is mediated by ROCK (Rho-associated, coiled-coil containing protein kinase), the effect of cumulative addition of the ROCK inhibitor Y-27632 to aortic rings precontracted with U46619 was studied. Under these conditions septic MPs did not affect the relaxation induced by Y-27632 compared with nonseptic MPs (Figure 2D). These results suggest that septic MP-induced hypersensitivity of mouse aorta is not mediated through either voltage-dependent $\mathrm{Ca}^{2+}$ channels or ROCK.

Septic MPs Do Not Inhibit Activity of NO Synthases and Cyclooxygenase-2, and Their Potentiating Effects Involve Vasoconstrictor Metabolites, Probably from Cyclooxygenase-1

To investigate the mechanisms involved in vascular hypersensitivity induced by septic MPs, the role of NOS and cyclooxygenase (COX)-2 metabolites was evaluated by studying the effect of pharmacologic inhibitors of these enzymes. $\mathrm{N}$-Nitro-Larginine (LNA) alone significantly enhanced contraction, but not the sensitivity to 5-HT, of aortas treated with both nonseptic
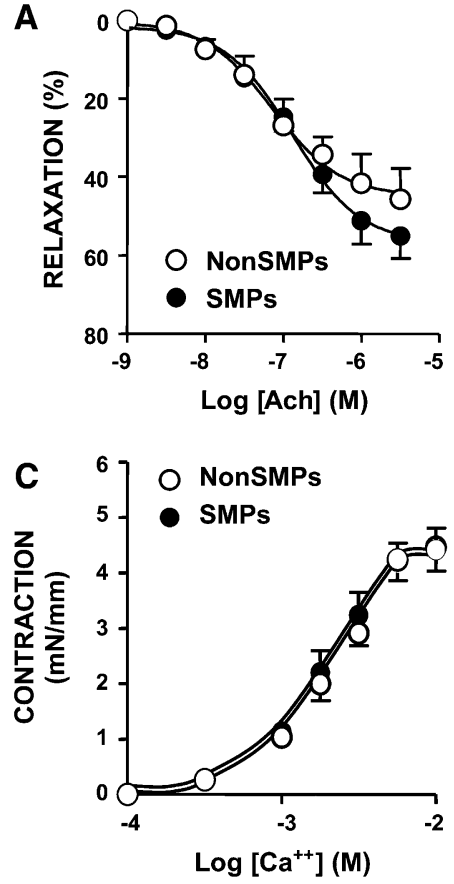
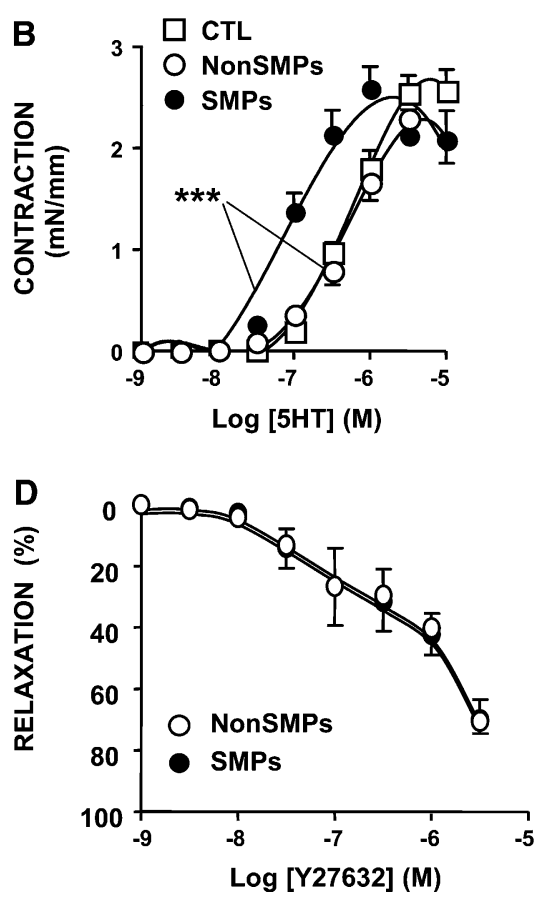

Figure 2. SMPs induce hypersensitivity to serotonin (5-HT) without impairment of endothelial vasodilation, voltage-dependent $\mathrm{Ca}^{2+}$ channels, or Rho kinase pathway. (A) Acetylcholine (ACh)-induced relaxation in nonSMP- and SMP-treated mouse aorta $(n=7)$. Results are expressed as a percentage of relaxation of U46619. induced precontraction. (B) Concentration-response curves to 5-HT of mouse aortic rings treated with nonSMPs $(\mathrm{n}=6)$ or SMPs $(\mathrm{n}=7)$. ${ }^{* * *} P<0.001$. (C) Concentration-response curves to increasing concentrations of $\mathrm{Ca}^{2+}$ of non-SMP- and SMP-treated mouse aorta $(\mathrm{n}=6)$. (D) Endothelium-dependent relaxation in response to cumulative addition of Rho kinase inhibitor ( $\mathrm{Y}$ 27632) of mouse aortas injected with either non-SMPs or SMPs $(n=6)$. Results are expressed as a percentage of relaxation of U46619-induced precontraction. 
and septic MPs $\left(\mathrm{E}_{\max }, 3.8 \pm 0.5\right.$ vs. $4.2 \pm 0.6 \mathrm{mN} / \mathrm{mm}$ and $\mathrm{pD}_{2}$, $6.58 \pm 0.03$ vs. $7.47 \pm 0.09$ from nonseptic MP- and septic MPtreated mice, respectively) (Figure 3A). However, LNA did not significantly modify the capacity of septic MPs in increasing the sensitivity to 5-HT.

Pretreatment with NS-398 alone did not significantly modify the contractile responses to 5-HT in septic MP-treated aortic rings compared with nonseptic $\mathrm{MP}-$ treated aortas $\left(\mathrm{E}_{\max }, 2.3 \pm\right.$ 0.6 vs. $2.7 \pm 0.6 \mathrm{mN} / \mathrm{mm}$ and $\mathrm{pD}_{2}, 6.47 \pm 0.05$ vs. $7.07 \pm 0.04$ from nonseptic MP- and septic MP-treated mice, respectively) (Figure 3B). Likewise, NS-398 did not affect the ability of septic MPs to enhance sensitivity to 5-HT. The combination of LNA and COX-2 inhibitor enhanced, to the same manner, contraction in response to $5-\mathrm{HT}\left(\mathrm{E}_{\max }, 3.35 \pm 0.53\right.$ vs. $4.3 \pm 0.47 \mathrm{mN} / \mathrm{mm}$ and $\mathrm{pD}_{2}, 6.49 \pm 0.04$ vs. $7.22 \pm 0.06$ from nonseptic MP- and septic MP-treated mice, respectively) (Figure 3C). This increase was similar in mouse aortic rings treated either with septic or nonseptic MPs. However, neither LNA nor the combination of LNA and NS-398 affected the increase in sensitivity induced by septic MPs in response to 5-HT. Altogether, these data suggest that the potentiating effect of septic MPs is not linked to any mechanism sensitive to NO synthase and COX-2 inhibitors.

To test the possible involvement of metabolites from a nonCOX-2 isoform in the effect of septic MPs, the nonselective COX inhibitor indomethacin was assessed. Under these conditions, indomethacin either reduced or abolished contraction, in response to 5-HT, of aortic rings taken from nonseptic MPand septic MP-treated mice, respectively $\left(\mathrm{E}_{\max }, 1.9 \pm 0.3\right.$ vs. $0.53 \pm 0.12 \mathrm{mN} / \mathrm{mm}$, respectively) (Figure $3 \mathrm{D}$ ). These results suggest that the effects of septic MPs on mouse aorta are probably mediated through vasoconstrictor COX-1 metabolites.

\section{Septic MPs Do Not Affect Expression of Enzymes Linked to $\mathrm{NO}$ and $\mathrm{O}_{2}^{-}$Production}

Aortic rings with functional endothelium from mice treated with either nonseptic or septic MPs, preincubated with diethyldithiocarbamate-iron(II) complex [Fe(DETC $)_{2}$, exhibited an electron paramagnetic resonance feature of signals derived from NO-Fe(DETC) 2 (data not shown). As shown in Figure 4A, septic MPs did not affect NO production compared with nonseptic MPs in aorta. Next, we investigated the pathways involved in MP-induced NO production. Both endothelial nitric oxide synthase (eNOS) expression and caveolin-1 expression were not significantly different in aorta from nonseptic $\mathrm{MP}-$ and septic MP-treated mice (Figures 4C and 4D). In addition, septic MPs did not affect iNOS expression (Figure 4E). Moreover, septic MP treatment did not affect NF- $\mathrm{B}$ expression (Figure

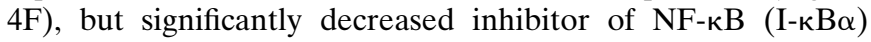
phosphorylation in mouse aorta compared with nonseptic MPs (Figure 4G).

Measurement of $\mathrm{O}_{2}{ }^{-}$production showed that septic MPs did not affect $\mathrm{O}_{2}{ }^{-}$production compared with nonseptic MPs in aorta (Figure 4B). Regarding the effects of septic MPs on expression of enzymes linked to $\mathrm{O}_{2}{ }^{-}$, septic MPs did not modify the Nox-1 isoform of NADPH oxidase (Figure 4H) but significantly decreased the Nox-4 isoform of this enzyme (Figure 4I) compared with nonseptic MPs in mouse aorta. Furthermore, septic MPs did not affect manganese superoxide dismutase (Mn-SOD) expression or copper/zinc superoxide dismutase $(\mathrm{Cu} / \mathrm{Zn}-\mathrm{SOD})$ expression (Figures $4 \mathrm{~J}$ and $4 \mathrm{~K}$, respectively). Altogether, these data showed that among the enzymes linked to $\mathrm{O}_{2}{ }^{-}$production, only Nox-4 expression was affected by septic MP treatment.

Septic MPs Do Not Affect COX-1 and COX-2 Expression, but They Stimulate Release of Thromboxane $A_{2}$

Although the expression levels of COX-1 and COX-2 enzymes were not different between aortic rings from septic MP- and nonseptic MP-treated mice (Figures 5A and 5B), their activity could be affected by this treatment. Assay of thromboxane $\mathrm{A}_{2}$ showed an increase in its production in aortas treated with septic MPs compared with those treated with nonseptic MPs (Figure $5 \mathrm{C})$. By contrast, release of either prostaglandin $\mathrm{E}_{2}, 8$-isoprostane, or prostacyclin was not significantly different between nonseptic MP- and septic MP-treated arteries (Figures 5D-5F).

To test the hypothesis that thromboxane $\mathrm{A}_{2}$ accounts for septic MP-induced hyperreactivity, aortic rings were incubated in the presence of SQ-29548, a specific thromboxane $\mathrm{A}_{2}$ receptor
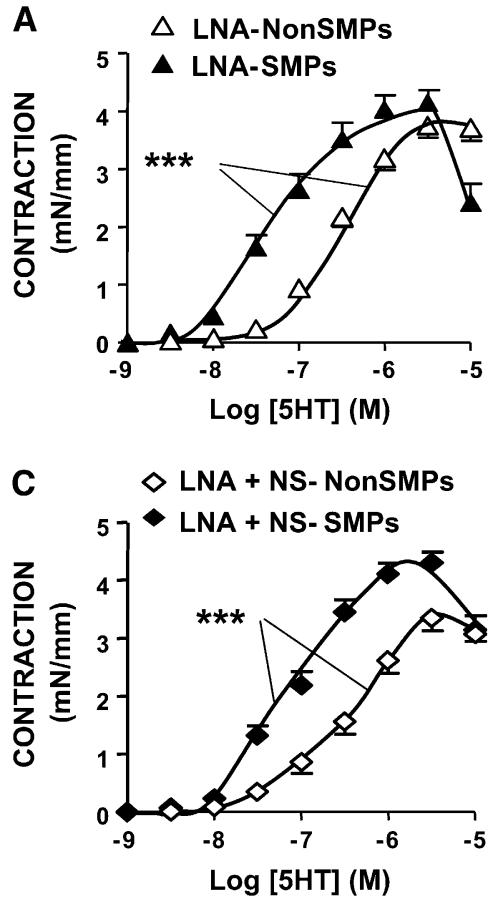
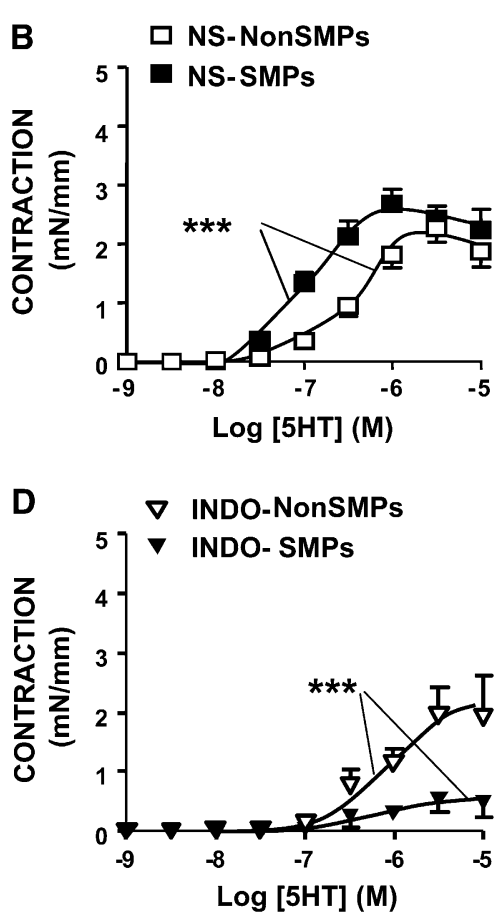

Figure 3. Effect of SMPs is not modified by the inhibition of either nitric oxide (NO) synthase or cyclooxygenase-2 but is greatly affected by indomethacin. Shown are concentration-response curves to 5-HT of mouse aortic rings treated with non-SMPs $(n=6)$ or SMPs $(n=7)$ in the presence of $(A) \mathrm{N}$-nitro-L-arginine (LNA), (B) NS-398 (NS), (C) LNA plus NS, or (D) indomethacin (INDO). $* * * P<0.001$. 

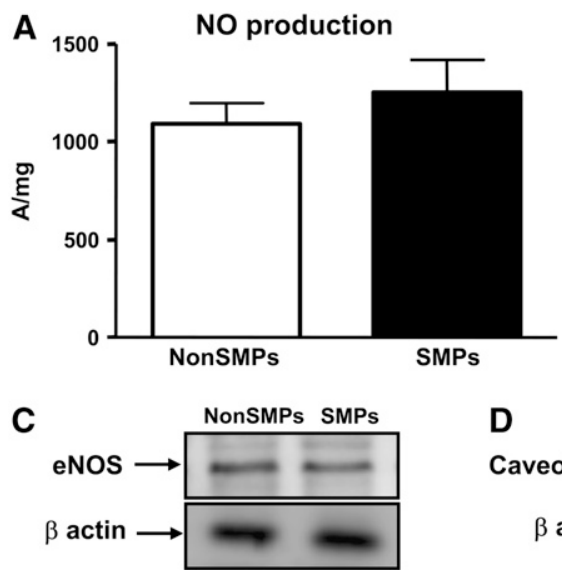

$\mathbf{F}$
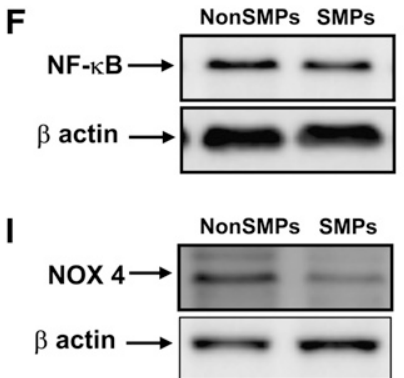
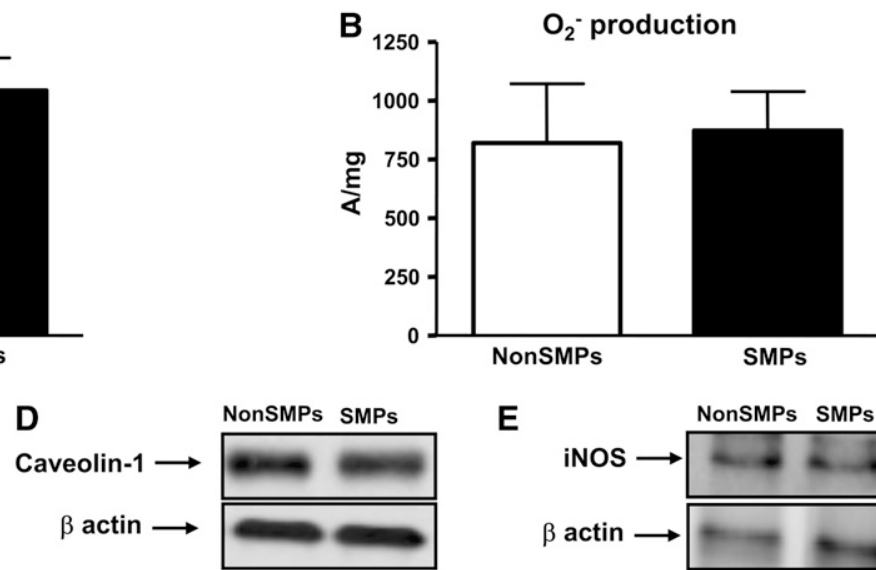

E

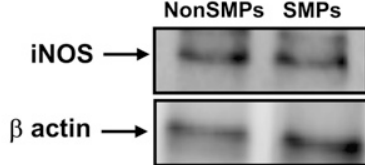

G

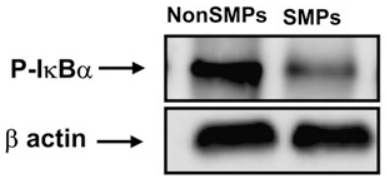

J

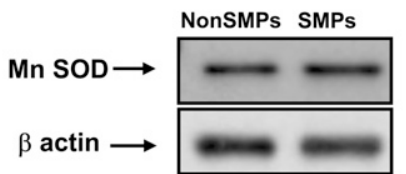

$\mathbf{H}$
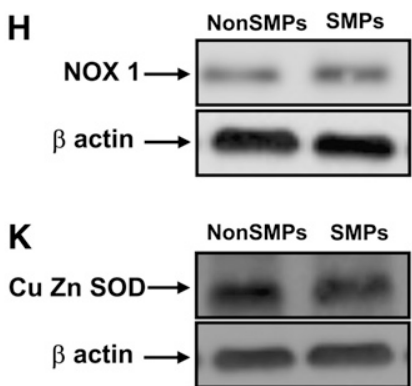

Figure 4. SMPs do not affect $\mathrm{NO}$ and $\mathrm{O}_{2}^{-}$production in mouse aorta. Quantification of the amplitude of (A) NO$\mathrm{Fe}(\mathrm{DETC})_{2}$ [diethyldithiocarbamate-iron(II) complex] and (B) $\mathrm{O}_{2}{ }^{-}-\mathrm{CMH}$ (1-hydroxy-3methoxycarbonyl-2,2,5,5-tetramethylpyrrolidine) signals in mouse aorta treated with either non-SMPs or SMPs. Values are expressed as units per milligram weight of dried aorta $(n=5)$. Western blots reveal expression of (C) endothelial nitric oxide synthase (eNOS), $(D)$ caveolin-1, $(E)$ inducible nitric oxide synthase (iNOS), $(F)$ nuclear factor (NF)-кB, (G) phosphorylated inhibitor of NF-кB $(\mathrm{I} \mathrm{B} \alpha),(H)$ Nox-, (I) Nox-4, (/) manganese superoxide dismutase (Mn SOD), $(K)$ and $\mathrm{Cu} / \mathrm{Zn}$ SOD in mouse aortas treated with either nonSMPs or SMPs $(n=4)$. antagonist, in an experimental model of sepsis using mice treated with LPS. As shown in Figure 6A, LPS treatment induced hyporeactivity of aortic rings in response to 5-HT compared with those taken from CTL mice $\left(\mathrm{E}_{\max }, 0.9 \pm 0.2\right.$ vs. $2.57 \pm 0.45 \mathrm{mN} / \mathrm{mm}$, respectively) $(P<0.05)$, and this effect was not modified by SQ-29548. Interestingly, septic MPs partially restored contraction in response either to 5-HT or phenylephrine in vessels taken from LPS-treated mice (Emax, $1.9 \pm 0.3$ and $1.7 \pm 0.15 \mathrm{mN} / \mathrm{mm}$ for 5 -HT and phenylephrine, respectively) (Figures 6B and 6C). In addition, the hyperreactivity induced by septic MPs in LPS-treated mice was abolished in the presence of SQ-29548 $\left(\mathrm{pD}_{2}, 6.3 \pm 0.04 ; \mathrm{E}_{\max }, 0.7 \pm 0.3 \mathrm{mN} / \mathrm{mm}\right)$ (Figure 6B).

Altogether, these results suggest that MPs from septic patients may be protective against vascular hyporeactivity during sepsis through the production of thromboxane $\mathrm{A}_{2}$.

\section{Vascular Effects of Differential Components of Circulating Septic MPs}

After separation of MP samples, two fractions were obtained: $\mathrm{CD} 1^{+}$MPs, which were selected from the platelet fraction, and
A
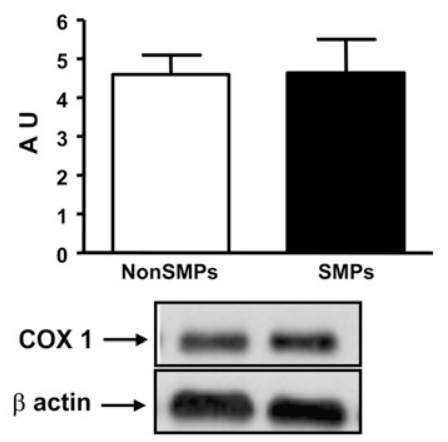

D

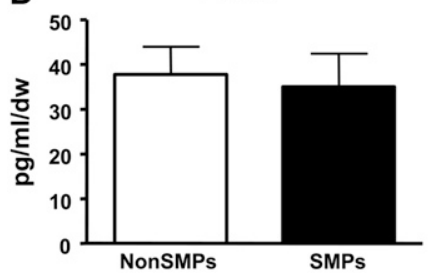

B

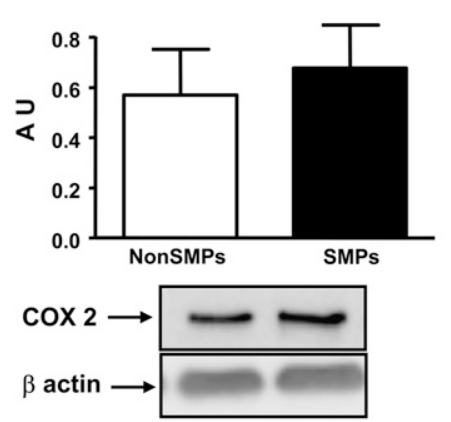

E

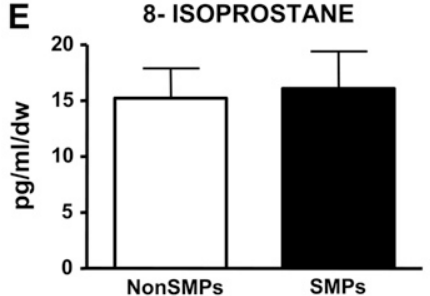

THROMBOXANE $\mathrm{A}_{2}$

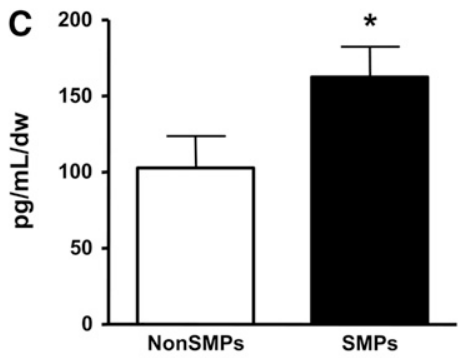

Figure 5. SMPs and prostaglandin production. Western blots reveal expression of $(A)$ cyclooxygenase (COX)-1 and $(B)$ COX-2 in mouse aortas treated with either non-SMPs or SMPs. Concentration of COX derivatives (C) thromboxane $\mathrm{A}_{2},(D)$ prostaglandin $\mathrm{E}_{2}\left(\mathrm{PGE}_{2}\right),(E)$ 8-isoprostane, and $(F)$ prostacyclin in the supernatants of mouse aortas pretreated with either non-SMPs or SMPs and stimulated with 5 -HT $(\mathrm{n}=4$ or 5$) .{ }^{*} \mathrm{P}<$ 0.05 . 

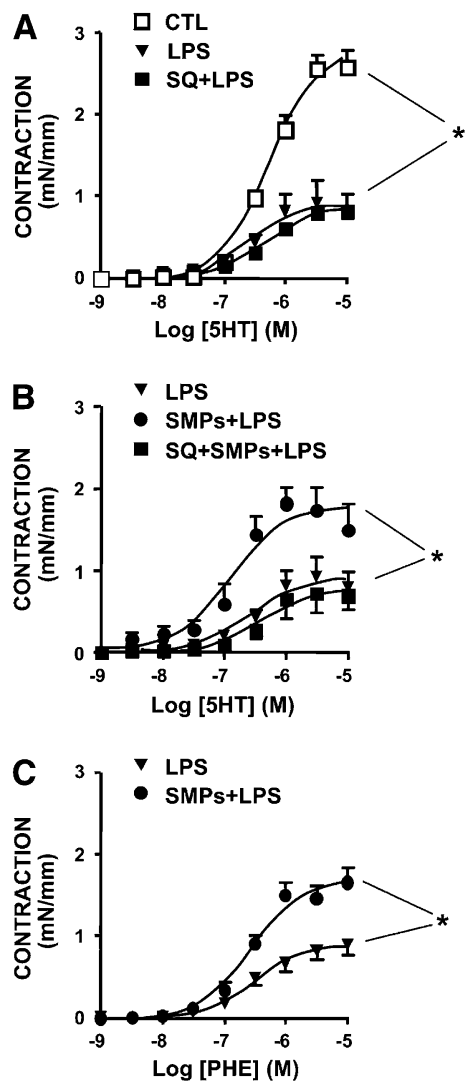

CD61- MPs of nonplatelet origin. Treatment with CD61 ${ }^{+}$MPs from septic patients did not significantly modify the contractile response to 5-HT when compared with treatment with nonseptic MPs $\left(E_{\max }, 1.9 \pm 0.2\right.$ vs. $2.3 \pm 0.2 \mathrm{mN} / \mathrm{mm}$ for $\mathrm{CD}^{+} 1^{+}$ $\mathrm{MP}-$ and nonseptic MP-treated mice, respectively) (Figure 7A). By contrast, CD61- MPs induced a slight but significantly increase in contraction induced by $5-\mathrm{HT}\left(\mathrm{E}_{\max }, 2.6 \pm 0.1 \mathrm{mN} / \mathrm{mm}\right)$ (Figure 7B). Thus, it is likely that MPs of nonplatelet origin account for the increase in contraction evoked by total septic MPs, whereas the increase in sensitivity to vasoconstrictors requires MPs of all origins.

\section{DISCUSSION}

In the present study, circulating levels of MPs are elevated in patients with septic shock compared with nonseptic subjects. Of particular interest was the increase in endothelial-derived, $\mathrm{P}_{\text {-selectin }}{ }^{+}$and L-selectin ${ }^{+}$MPs in addition to platelet-derived
MPs in septic shock patients. In addition, levels of MPs from leukocytes were decreased. Furthermore, we provide evidence of the physiological relevance of septic MPs in the regulation of vascular contraction. Surprisingly, septic MPs enhanced, but did not reduce, the sensitivity of contraction in response to 5-HT without affecting endothelium-dependent vasodilation. Interestingly, septic microparticles enhanced the contraction of aortas from LPS-treated mice. This effect was linked neither to increased calcium entry nor to Rho kinase inhibitor-sensitive mechanisms. In addition, the effect of septic MPs was not modified in the presence either of NO synthase inhibitor or COX-2 inhibitor, and was not associated with changes in $\mathrm{NO}$ or $\mathrm{O}_{2}{ }^{-}$production. The nonselective $\mathrm{COX}$ inhibitor, indomethacin, either reduced or abolished contraction to 5-HT in aorta from mice treated with nonseptic and septic MPs, respectively. The effect of septic MPs was not linked to changes in COX-1 and COX-2 expression but was associated both with a mechanism sensitive to the thromboxane $\mathrm{A}_{2}$ receptor antagonist, SQ29548, and increased thromboxane $\mathrm{A}_{2}$ production. Thus, septic MPs may, rather, be protective in counteracting the drop in peripheral resistance and progressive hypotension during severe sepsis under the experimental conditions used. These results may also explain the fact that increased levels of MPs may predict a more favorable outcome in severe sepsis in terms of mortality rate and organ dysfunction (8).

Several studies provide information about the probable role of circulating MPs in the coagulation process that leads to disseminated intravascular coagulation during sepsis $(6,7)$. In the present study, we confirm the increase in circulating levels of MPs exposing P-selectin and L-selectin in patients with sepsis. P-selectin and L-selectin so expressed may become potent contributors to thrombus initiation and propagation, and most importantly inflammation, respectively. In addition, the fact that MPs from leukocytes are decreased in septic patients could reflect the sequestration of leukocytes in remote organs as it has been reported in endotoxin models of sepsis (18).

Several pathologies are associated with vascular dysfunction including attenuation of endothelium-dependent vasodilation and/or alteration of responsiveness of vascular smooth muscle to vasoconstrictor stimuli. Sepsis is in general associated with reduced endothelium-dependent vasodilation and vascular hyporesponsiveness to vasoconstrictor agonists in differential experimental models of endotoxemia. In our previous studies, both endothelium-dependent vasodilation and contractile responses of small omental arteries from septic patients are not significantly changed ex vivo despite the fact that they are removed from patients whose peripheral resistance and blood pressure are dramatically reduced (10). A hyperreactivity to agonists has been shown in these arteries, which compensates for the increased production of $\mathrm{NO}$, in conjunction with vasodilatory products from $\mathrm{COX}$ metabolites. However, the cellular process
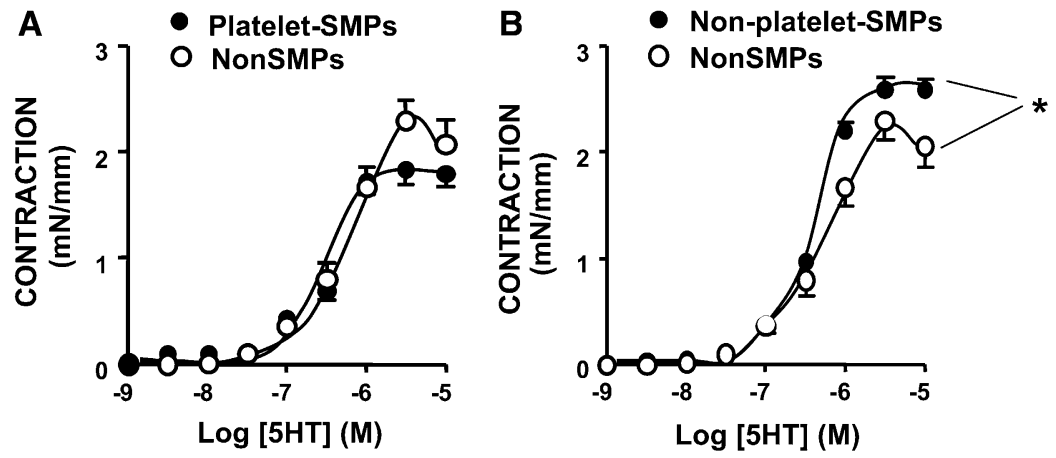

Figure 7. Effects of platelet or nonplatelet SMPs on 5-HT-induced contraction of mouse aortic rings. Concentration-responsecurves to 5-HT of aortic rings from non-SMP-treated mice and $(A)$ platelet SMP-treated mice and $(B)$ nonplatelet SMP-treated mice $(n=5$ or 6$)$. $\star P<0.05$ 
and the mechanisms of this vascular alteration during septic shock have not been completely deciphered, especially regarding the role of MPs.

Previous studies have shown that MPs are implicated in the regulation of vascular tone (4). Indeed, it has been reported that MPs from patients with diabetes, HIV infection, or end-stage renal failure are able to induce endothelial dysfunction in ex vivo-treated vessels $(13,16)$. In the present study, injection of septic MPs into mice did not induce endothelial dysfunction compared with nonseptic MPs. In conjunction with these functional data, septic MPs did not modify eNOS and caveolin-1 expression and NO production, and they did not trigger endothelial dysfunction under the experimental condition used. Consistent with these results, we have previously shown that MPs from women with preeclampsia did not affect endothelial function (14).

Concerning vascular reactivity to vasoconstrictor stimuli, we previously reported that in vivo treatment of mice with human lymphocyte-derived MPs or MPs from preeclamptic women induces vascular hyporesponsiveness to vasoconstrictor agents $(14,15)$. In the present study, MPs from septic patients increased rather than decreased the sensitivity to $5-\mathrm{HT}$, as shown by the significant leftward shift of the concentration-effect curves of this agonist, compared with aorta from nonseptic MP-treated mouse. These data support the view that septic MPs participate in the mechanisms that counteract the increased NO production and vasodilatory COX metabolites reported in small omental arteries from septic shock patients (10).

The mechanisms associated with the increase in vascular sensitivity to vasoconstrictor agents in response to septic MPs were further studied in terms of $\mathrm{Ca}^{2+}$ handling and sensitization. Our previous studies indicate that mechanisms leading to contraction elicited by agonist are composed of $\mathrm{Ca}^{2+}$ release from intracellular stores, $\mathrm{Ca}^{2+}$ influx and $\mathrm{Ca}^{2+}$ sensitization, and/or $\mathrm{Ca}^{2+}$ independent pathways $(19,20)$. The latter involved tyrosine kinase, protein kinase $\mathrm{C}$, and Rho kinase. We found that the increased sensitivity to vasoconstrictor agonist after septic MP treatment was linked neither to increased $\mathrm{Ca}^{2+}$ entry nor Rho kinase inhibitor-sensitive mechanisms. It cannot be excluded that an increase in intracellular $\mathrm{Ca}^{2+}$ might be involved, as was previously found in small arteries from endotoxin-treated rats (21).

In the present study, septic MPs compared with nonseptic MPs did not produce oxidative stress in the vessel wall, as shown by the lack of effect of septic MPs in altering $\mathrm{O}_{2}{ }^{-}$ production. NADPH oxidases (mainly gp91 ${ }^{\text {phox }}$ and the homo$\log$ Nox-1 and Nox-4 subunits) are a major enzymatic source of $\mathrm{O}_{2}{ }^{-}$in the vasculature and are present in major cell types that make up the vessel wall (i.e., endothelial cells, smooth muscle cells, and adventitial fibroblasts) $(22,23) . \mathrm{O}_{2}{ }^{-}$is reduced to hydrogen peroxide in the presence of ubiquitously distributed SOD enzymes (24). Endogenous SOD isoforms keep $\mathrm{O}_{2}{ }^{-}$levels under tight control. However, in many disease states including sepsis there is an imbalance between the amount of $\mathrm{O}_{2}{ }^{-}$formed and the ability of SOD enzymes to remove $\mathrm{O}_{2}{ }^{-}$. Here, septic MPs did not modify Nox-1, Mn-SOD, and Cu/Zn-SOD expression compared with nonseptic MPs. Moreover, Nox-4 expression was decreased in septic MP-treated aorta of mice compared with those treated with nonseptic MPs. Interestingly, Martyn and coworkers (25) have reported that Nox-4, in contrast to other Nox proteins, produces large amounts of hydrogen peroxide constitutively. One can advance the hypothesis that the decrease in Nox-4 expression induced by septic MPs might be associated with a decrease in hydrogen peroxide production. All of these results suggest that septic MPs might not be responsible for the increase in oxidative stress in the vessel wall during sepsis, the latter being, under certain circumstances, involved in the increased vascular smooth muscle contraction (26).

Sepsis, like other inflammatory conditions, results in the synthesis of acute-phase inflammatory mediators including NO from iNOS and COX-2 metabolites under the activation of NF$\kappa B$. Such an effect might lead to intense vasodilation, and subsequent potential hypotension such as that observed in severe sepsis. In the present study, septic MP treatment did

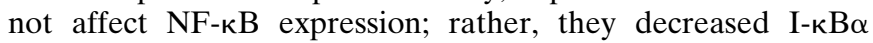
phosphorylation in aortas compared with nonseptic MPs. Furthermore, after pharmacologic blockade of either NO synthase with LNA or of COX-2 with NS-398 alone or in combination with LNA, septic MPs were still able to increase vascular sensitivity to 5-HT. Moreover, on septic MP treatment, aortic NO content and iNOS and COX-2 expression were not different from that of vessels taken from nonseptic MP-treated mice. Altogether, these data demonstrate that septic MPs are not the biological vectors that trigger vascular inflammation linked to nitrosative stress and increased COX-2 metabolites during severe sepsis.

Interestingly, treatment with indomethacin, the nonselective COX inhibitor, abolished contraction to 5-HT only in aortic rings from mice treated with septic MPs, whereas contraction induced by 5-HT in aortas from mice treated with nonseptic MPs was only reduced. In addition, indomethacin alone had no effect on contraction induced by 5-HT in the absence of MP treatment. These results suggest the involvement of vasoconstrictor products from $\mathrm{COX}$ and probably COX-1 because NS398 did not modify the potentiating capacity of septic MPs. The effect of septic MPs was not linked to changes in COX-1 expression but was associated with increased thromboxane $\mathrm{A}_{2}$ production without any modification of prostaglandin $E_{2}$, 8-isoprostane, or the vasodilator prostacyclin. It is likely that the increased sensitivity to vasoconstrictor in response to septic MPs is the consequence of increased thromboxane $\mathrm{A}_{2}$ from COX-1. Indeed, specific thromboxane $A_{2}$ antagonist reduced contraction, in response to 5-HT, of aortic rings taken from septic MP-treated mice. This strengthened the hypothesis that septic MPs might be the vector able to counteract the increased production of $\mathrm{NO}$ and $\mathrm{COX}$ vasodilator metabolites observed in vessels from septic shock patients, with the cautions that experiments were performed on conductance arteries from mice treated with septic MPs.

Moreover, to better provide evidence of the protective effects of septic MPs on vascular reactivity during septic shock, we have studied their function in an endotoxic model induced with LPS. Interestingly, septic MPs were able to partially restore hyporeactivity after administration of LPS. Thus, these results reinforce the hypothesis that septic MPs may be protective against vascular hyporeactivity during the early phase of sepsis.

Finally, the results obtained with the differential components of septic MPs suggest that MPs of nonplatelet origin account at least partially for the increase in contraction evoked by septic MPs. These results also highlight the notion that MPs of all cellular origins are needed to induce the increase in sensitivity to vasoconstrictor agent obtained in the present study, although those from platelets alone are ineffective.

In summary, we report that septic patients displayed increased circulating MPs, especially those originated from nonactivated and activated platelets and endothelial and activated leukocytes. Furthermore, we demonstrate that although septic MPs may be a link between inflammation and thrombosis observed in sepsis, they may be protective against vascular hyporeactivity by maintaining a tonic pressor response in septic shock patients. These data create a mechanistic basis for the 
correlation between increased circulating MPs and better survival rate among patients in the early phase of septic shock.

Conflict of Interest Statement: None of the authors has a financial relationship with a commercial entity that has an interest in the subject of this manuscript.

\section{References}

1. Balk RA. Severe sepsis and septic shock. Crit Care Clin 2000;16:179-192.

2. Levy MM, Fink MP, Marshall JC, Abraham E, Angus D, Cook D, Cohen J, Opal SM, Vincent JL, Ramsay G; SCCM/ESICM/ACCP/ ATS/SIS. 2001 SCCM/ESICM/ACCP/ATS/SIS International Sepsis Definitions Conference. Crit Care Med 2003;31:1250-1256.

3. Galley HF, Webster NR. The immunoinflammatory cascade. Br J Anaesth 1996;77:11-16.

4. Martínez MC, Tesse A, Zobairi F, Andriantsitohaina R. Shed membrane microparticles from circulating and vascular cells in regulating vascular function. Am J Physiol 2005;288:H1004-H1009.

5. Hugel B, Martinez MC, Kunzelmann C, Freyssinet JM. Membrane microparticles: two sides of the coin. Physiology (Bethesda) 2005;20: 22-27.

6. Nieuwland R, Berckmans RJ, McGregor S, Böing AN, Romijn FP, Westendorp RG, Hack CE, Sturk A. Cellular origin and procoagulant properties of microparticles in meningococcal sepsis. Blood 2000;95: 930-935.

7. Aras O, Shet A, Bach RR, Hysjulien JL, Slungaard A, Hebbel RP, Escolar G, Jilma B, Key NS. Induction of microparticle- and cellassociated intravascular tissue factor in human endotoxemia. Blood 2004:103:4545-4553.

8. Soriano AO, Wenche J, Chirinos JA, Valdivia MA, Velasquez HS, Jimenez JJ, Horstman LL, Kett DH, Schein RM, Ahn YS. Levels of endothelial and platelet microparticles and their interactions with leukocytes negatively correlate with organ dysfunction and predict mortality in severe sepsis. Crit Care Med 2005;33:2540-2546.

9. Assreuy J. Nitric oxide and cardiovascular dysfunction in sepsis. Endocr Metab Immune Disord Drug Targets 2006;6:165-173.

10. Stoclet JC, Martinez MC, Ohlmann P, Chasserot S, Schott C, Kleschyov AL, Schneider F, Andriantsitohaina R. Induction of nitric oxide synthase and dual effects of nitric oxide and cyclooxygenase products in regulation of arterial contraction in human septic shock. Circulation 1999;100:107-112.

11. American College of Chest Physicians, Society of Critical Care Medicine. Consensus conference: definitions for sepsis and organ failure and guidelines for the use of innovative therapies in sepsis. Crit Care Med 1992;20:864-874.

12. Martínez MC, Larbret F, Zobairi F, Coulombe J, Debili N, Vainchenker W, Ruat M, Freyssinet JM. Transfer of differentiation signal by membrane microvesicles harboring Hedgehog morphogens. Blood 2006;108:3012-3020.

13. Amabile N, Guerin AP, Leroyer A, Mallat Z, Nguyen C, Boddaert J, London GM, Tedgui A, Boulanger CM. Circulating endothelial microparticles are associated with vascular dysfunction in patients with end-stage renal failure. J Am Soc Nephrol 2005;16:3381-3388.

14. Meziani F, Tesse A, David E, Martinez MC, Wangesteen R, Schneider F, Andriantsitohaina R. Shed membrane particles from preeclamptic women generate vascular wall inflammation and blunt vascular contractility. Am J Pathol 2006;169:1473-1483.

15. Tesse A, Martinez MC, Hugel B, Chalupsky K, Muller CD, Meziani F, Mitolo-Chieppa D, Freyssinet JM, Andriantsitohaina R. Upregulation of pro-inflammatory proteins through NF-кB pathway by shed membrane microparticles results in vascular hyporeactivity. Arterioscler Thromb Vasc Biol 2005;25:2522-2527.

16. Martin S, Tesse A, Hugel B, Martinez MC, Morel O, Freyssinet JM, Andriantsitohaina R. Shed membrane particles from T lymphocytes impair endothelial function and regulate endothelial protein expression. Circulation 2004;109:1653-1659.

17. Khoo JP, Alp NJ, Bendall JK, Kawashima S, Yokoyama M, Zhang YH, Casadei B, Channon KM. EPR quantification of vascular nitric oxide production in genetically modified mouse models. Nitric Oxide 2004; 10:156-161.

18. Piper RD, Pitt-Hyde ML, Anderson LA, Sibbald WJ, Potter RF. Leukocyte activation and flow behavior in rat skeletal muscle in sepsis. Am J Respir Crit Care Med 1998;157:129-134.

19. Lagaud GJ, Randriamboavonjy V, Roul G, Stoclet JC, Andriantsitohaina R. Mechanism of $\mathrm{Ca}^{2+}$ release and entry during contraction elicited by norepinephrine in rat resistance arteries. Am J Physiol 1999;276:H300-H308.

20. Martinez MC, Randriamboavonjy V, Ohlmann P, Komas N, Duarte J, Schneider F, Stoclet JC, Andriantsitohaina R. Involvement of protein kinase $\mathrm{C}$, tyrosine kinases, and Rho kinase in $\mathrm{Ca} 2+$ handling of human small arteries. Am J Physiol Heart Circ Physiol 2000;279: H1228-H1238.

21. Martínez MC, Muller B, Stoclet JC, Andrihantsitohaina R. Alteration by lipopolysaccharide of the relationship between intracellular calcium levels and contraction in rat mesenteric artery. Br J Pharmacol 1996; 118:1218-1222.

22. Griendling KK, Sorescu D, Ushio-Fukai M. NAD(P)H oxidase: role in cardiovascular biology and disease. Circ Res 2000;86:494-501.

23. Lassègue B, Sorescu D, Szöcs K, Yin Q, Akers M, Zhang Y, Grant SL, Lambeth JD, Griendling KK. Novel gp91 phox homologues in vascular smooth muscle cells: Nox1 mediates angiotensin II-induced superoxide formation and redox-sensitive signaling pathways. Circ Res 2001; 88:888-894.

24. Salvemini D, Cuzzocrea S. Therapeutic potential of superoxide dismutase mimetics as therapeutic agents in critical care medicine. Crit Care Med 2003;31:S29-S38.

25. Martyn KD, Frederick LM, von Loehneysen K, Dinauer MC, Knaus UG. Functional analysis of Nox4 reveals unique characteristics compared to other NADPH oxidases. Cell Signal 2006;18:69-82.

26. Rathore R, Zheng YM, Li XQ, Wang QS, Liu QH, Ginnan R, Singer HA, Ho YS, Wang YX. Mitochondrial ROS-PKCe signalling axis is uniquely involved in hypoxic increase in $\left[\mathrm{Ca}^{2+}\right]_{\mathrm{i}}$ in pulmonary artery smooth muscle cells. Biochem Biophys Res Commun 2006;351:784790. 